and on various members of the superstructure to determine the manner in which the loads were carried down to the pintle.

Gange lines were placed on two opposite sides of every member tested, and where possible, on all four sides. Gauge lines were laid out on the deck of the pontoon for the purpose of determining the amount of stress developed in the plates of the pontoon deck and to check the computed locations of the maximum bending moments.

Strain-gauge readings were taken with a Io-inch Berry StrainGuage, it being possible to read the change of length between the points of the instruments directly to the nearest 0.0002 inch, and by estimation to 0.00002 inch.

The material used for loading the crane consisted chiefly of armor plate and scrap iron of known weight. The loading was so arranged that each member on which measurements were taken, was subjected to the maximum possible range of stress.

The strain-gauge work done on this structure showed that all stresses on the various members were within safe limits.

The stresses in the deck were found to be low.

The maximum stresses in the outer erlge of the tower legs are I 7 , ooo pounds per square inch compression and 3,5 oo pounds per square inch tension.

The maximum stress in the pintle post is 18,000 pounds per square inch compression.

The stresses in the superstructure and in the luffing screws due to the load are not excessive.

\title{
CEMENTS FOR SPARK PLUGS. ${ }^{*}$
}

\section{By Homer F. Staley.}

[ABSTRACT.]

THE use of cements for sealing electrodes into spark-plug porcelains has been found to be attended by serious difficulties in high temperature engines such as airplanes. Among these are: promotion of oxidation and destruction of the electrode wires by reactions taking place in the cement and between the cement and electrode wires; breaking of spark-plug porcelains caused by difference in coefficients of thermal expansion of electrode wires

${ }^{5}$ Technologic Paper No. I55. 
and porcelain; and cracking of cement, with consequent gas leakage, due to the same cause. A cement composed of silicate of soda and raw kaolin has been found to give little trouble from chemical action. In order to avoid the difficulties attending the use of any form of cement, the use of a mechanical seal at the top of the porcelain has been tried with promising results.

\section{AREA MEASUREMENT OF LEATHER. ${ }^{*}$}

\section{By Frederick J. Schlink.}

[ABSTRACT,]

THIs paper deals with the investigation of area measuring machines used for integrating the area of leather hides and skins. 'The importance of the problem of area measurement in view of the enormous amount and value of leather handled annually on this basis $(\$ 450,000,000$ in U. S. A. ) is indicated. The principles of design involved in typical machines are set forth in detail and an analysis is made of the sources of the serious errors which commonly exist and of the means available for detecting and correcting them, including a complete regime for the determination of the performance of the machine tested with regard to both the accuarcy and consistency of its determinations. Numerical data illustrative of the various errors and performance characteristics of typical measuring machines are tabulated in detail.

\section{HYDROGEN ION CONCENTRATION IN DRY CELLS.}

\section{By H. D. Holler.}

\section{[ABSTRACT.]}

THE potentials of electrodes consisting of mixtures of Acheson graphite with three different manganese ores and a chemically prepared oxide were measured in ammonium chloride solutions of different hydrogen ion concentrations. The potential of the electrodes containing the ores was found to be a logarithmic function of the hydrogen ion concentration, while the potential of electrodes containing the chemically prepared oxide was found to be independent of hydrogen ion concentration. The potential

- Technologic Paper No. I53.

${ }^{7}$ Scientific Paper No. 364 . 